\title{
Deep-red to near-infrared electrophosphorescence based on bis(8-hydroxyquinolato) platinum(II) complexes
}

\author{
Hai-Feng Xiang, ${ }^{1,2}$ Zong-Xiang Xu, ${ }^{1}$ V. A. L. Roy, ${ }^{1}$ Bei-Ping Yan, ${ }^{1}$ Siu-Chung Chan, ${ }^{1}$ \\ Chi-Ming Che, ${ }^{1, a)}$ and P. T. Lai ${ }^{2}$ \\ ${ }^{1}$ Department of Chemistry and HKU-CAS Joint Laboratory on New Materials, The University of Hong \\ Kong, Pokfulam Road, HKSAR, China \\ ${ }^{2}$ Department of Electrical \& Electronic Engineering, The University of Hong Kong, Pokfulam Road, \\ HKSAR, China
}

(Received 13 February 2008; accepted 15 March 2008; published online 22 April 2008)

\begin{abstract}
A series of neutral platinum(II) complexes with substituted 8-hydroxyquinoline ligands for use in organic electroluminescent devices have been prepared. These platinum(II) complexes give deep-red to near-infrared phosphorescence with $\lambda_{\text {max,peak }}$ from 650 to $695 \mathrm{~nm}$ and $\lambda_{\text {max,shoulder }}$ from 705 to $755 \mathrm{~nm}$. High-performance organic light-emitting devices are obtained using these bis(8-hydroxyquinolato) platinum(II) complexes as a deep-red to near-infrared emitter with maximum external quantum efficiency, luminous efficiency, and turn-on voltage of $1.7 \%$, $0.32 \mathrm{~cd} / \mathrm{A}$, and $3.2 \mathrm{~V}$, respectively. (C) 2008 American Institute of Physics.
\end{abstract}

[DOI: 10.1063/1.2906892]

In recent years, highly efficient phosphorescent organic light-emitting devices (OLEDs) have received growing attention because the harvest of both singlet and triplet excitons enables the achievement of a maximum internal quantum efficiency of $100 \% .^{1-5}$ However, most works were directed toward light emission in the visible spectral region. Extending OLED emission into near-infrared (NIR) wavelength is a challenging task, despite the useful applications of NIR OLEDs in optical communication and biomedical sensings. To date, most organic NIR electroluminescent (EL) ma- terials have a low external quantum efficiency $\left(\eta_{\text {ext }}\right){ }^{6-10}$ except for the $\mathrm{Pt}(\mathrm{II})$ tetraphenyltetrabenzoporphyrin (Refs. 11 and 12) and $[\mathrm{Pt}(\mathrm{L}) \mathrm{Cl}] \quad[\mathrm{L}=1,3$-di(2-pyridyl)benzene $]$ complexes, ${ }^{13}$ both of which have a $\eta_{\text {ext }}$ more than $5 \%$.

The first efficient OLED, demonstrated by Tang and VanSlyke, was based on tris(8-hydroxyquinolato) aluminu$\mathrm{m}(\mathrm{III})\left(\mathrm{Alq}_{3}\right.$, Fig. 1). ${ }^{1}$ Since then, $\mathrm{Alq}_{3}$ has been widely used as an electron-transporting material, green fluorescent emitter, or host material for various dyes to tune the emission color from green to red. The $\mathrm{Alq}_{3}$ material has a good ther-
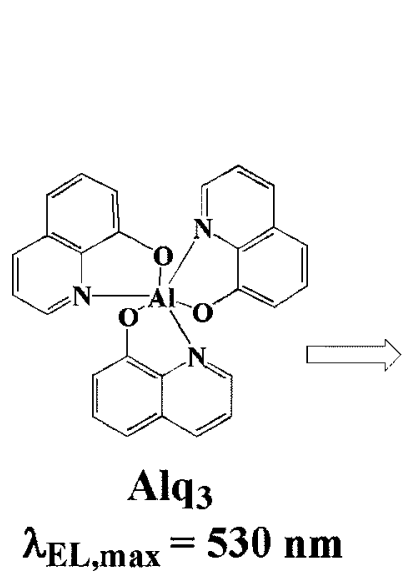
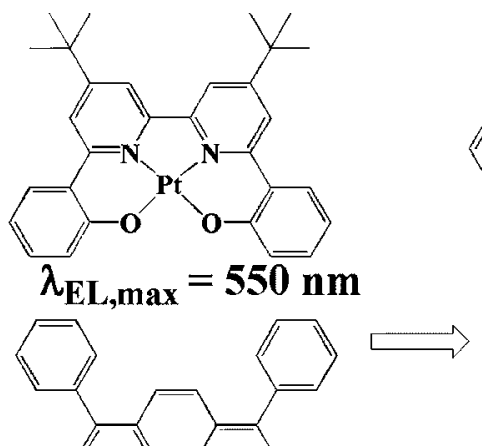

Ref. 16

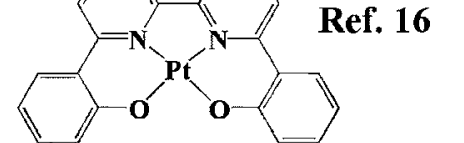

$$
\lambda_{\mathrm{EL}, \max }=588 \mathrm{~nm}
$$

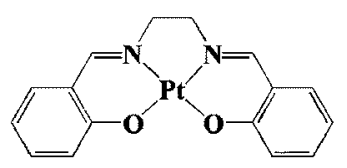

$\lambda_{\mathrm{EL}, \max }=555 \mathrm{~nm}$

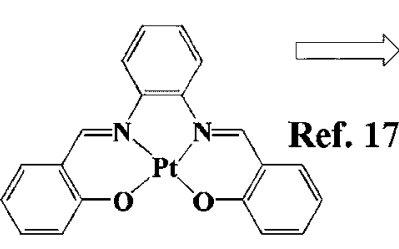

$\lambda_{\mathrm{EL}, \max }=630 \mathrm{~nm}$<smiles></smiles>

$\operatorname{Pt}\left(\mathrm{Cl}_{\mathbf{2}} \mathbf{q}\right)_{2}$<smiles>c1cc2cccc3op4oc5cccc6pccc(oc(c1)c2n34)c56</smiles>

$\mathbf{P t q}_{2}$

$\operatorname{Pt}\left(\mathrm{Cl}_{2} \mathrm{Meq}\right)_{2}$

FIG. 1. Chemical structures of $\mathrm{Alq}_{3}$ and $\mathrm{Pt}(\mathrm{II})$ complexes.

\footnotetext{
${ }^{a)}$ Electronic mail: cmche@hku.hk.
} 

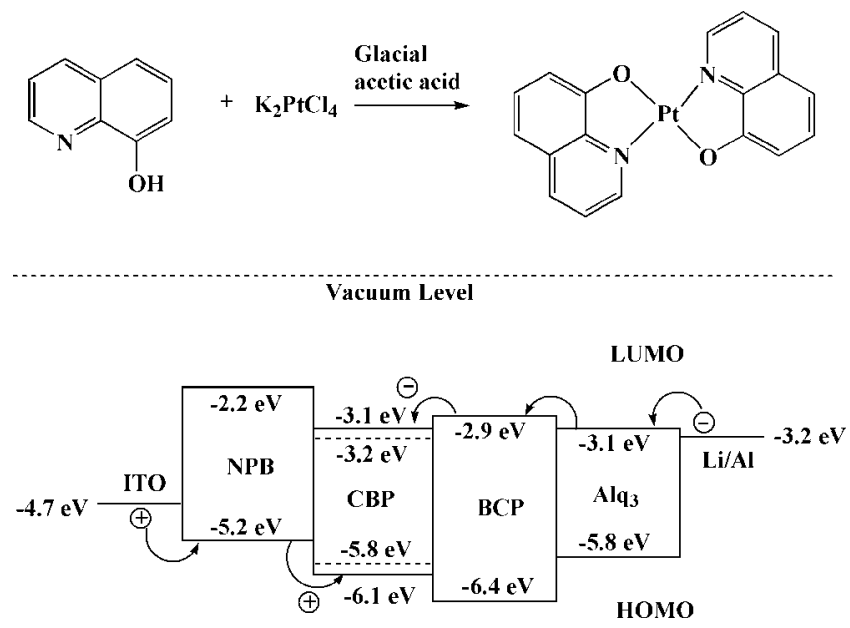

FIG. 2. Synthetic methodology of $\mathrm{Ptq}_{2}$ complex and schematic energy diagrams of organic materials used in this work (dash line for $\mathrm{Ptq}_{2}$ complex).

mal and morphological stability that allows the formation of good-quality thin film by vacuum deposition. ${ }^{14,15}$ Our previous work demonstrated efficient yellow-red OLEDs based on $\mathrm{Pt}(\mathrm{II})$ complexes containing the tetradentate or tridentate hydroxyquinolato ligands and their derivatives, ${ }^{16-18}$ as shown in Fig. 1. In this work, upon combining the large spin-orbital coupling effect of $\mathrm{Pt}(\mathrm{II})$ ion and the desirable thin-film property of 8-hydroxyquinolato metal complexes, a series of neutral phosphorescent bis(8-hydroxyquinolato) platinum(II) complexes, bis(8-hydroxyquinolato) platinum(II) $\left(\mathrm{Ptq}_{2}\right)$, bis(5,7-dichloro-8-hydroxquinolato) platinum(II) $\left[\mathrm{Pt}^{(}\left(\mathrm{Cl}_{2} \mathrm{q}\right)_{2}\right]$, and bis(5,7-dichloro-2-methyl-8-hydroxyquinolato) platinu$\mathrm{m}$ (II) $\left[\mathrm{Pt}\left(\mathrm{Cl}_{2} \mathrm{Meq}\right)_{2}\right]$ (Fig. 1), have been prepared and used to fabricate deep-red to NIR OLEDs.

All the bis(8-hydroxquinolato) platinum(II) complexes were synthesized by a one-step reaction using Scandola's method, ${ }^{19,20}$ as depicted in Fig. 2. All NIR EL devices were prepared on patterned indiumtin-oxide (ITO) glass with a sheet resistance of 20 $\Omega / \square$. The configuration of the OLEDs was ITO/ $N, N^{\prime}$-bis(naphthyl)- $N, N^{\prime}$-diphenyl-1, $1^{\prime}$-biphenyl-4, $4^{\prime}$-diamine (NPB) $\quad(40 \mathrm{~nm}) / 4,4 /-\mathrm{N}, \mathrm{N} /$-dicarbazole-biphenyl (CBP): Pt(II) complex (30 nm)/ 2,9-dimethyl-4,7-diphenyl1,10-phenanthroline (BCP) $(10 \mathrm{~nm}) / \mathrm{Alq}_{3} \quad(30 \mathrm{~nm}) / \mathrm{LiF}$ $(0.5 \mathrm{~nm}) / \mathrm{Al}(150 \mathrm{~nm})$. NPB was employed as hole-transport material, while $\mathrm{BCP}$ was used as hole-blocking material. $\mathrm{Alq}_{3}$ was chosen as electron-transport material. All layers of the OLEDs were grown on the matrix layer by thermal evaporation under a vacuum of $1.0 \times 10^{-6}$ Torr.

Thermogravimetric analysis showed that the decomposition temperatures of the complexes, $\operatorname{Ptq}_{2}, \operatorname{Pt}\left(\mathrm{Cl}_{2} \mathrm{q}\right)_{2}$, and $\mathrm{Pt}\left(\mathrm{Cl}_{2} \mathrm{Meq}\right)_{2}$, are 382,431 , and $413{ }^{\circ} \mathrm{C}$, respectively. As depicted in Fig. 3, thin films of the $\mathrm{Pt}(\mathrm{II})$ complexes individually exhibited a deep-red to NIR photoluminescence (PL) $\left(\lambda_{\text {max,peak }} 650-695 \mathrm{~nm}\right.$ and $\lambda_{\text {max,shoulder }} 705-755 \mathrm{~nm}$ ) with vibrational spacing of $1100-1400 \mathrm{~cm}^{-1}$, the latter is characteristic of the ring-breathing mode of 8-quinolinolato ligands. $\mathrm{Ptq}_{2}$ is soluble in common organic solvents, while $\mathrm{Pt}\left(\mathrm{Cl}_{2} \mathrm{q}\right)_{2}$ is slightly soluble in $N, N$-dimethylformamide (DMF), and $\mathrm{Pt}\left(\mathrm{Cl}_{2} \mathrm{Meq}\right)_{2}$ is insoluble in common organic solvents. In DMF solution, the PL emission of $\mathrm{Ptq}_{2}$ and $\mathrm{Pt}\left(\mathrm{Cl}_{2} \mathrm{q}\right)_{2}$ are similar with $\lambda_{\max }$ at 650 and $666 \mathrm{~nm}$, and emission decay lifetime of 4.8 and $3.7 \mu \mathrm{s}$, respectively,

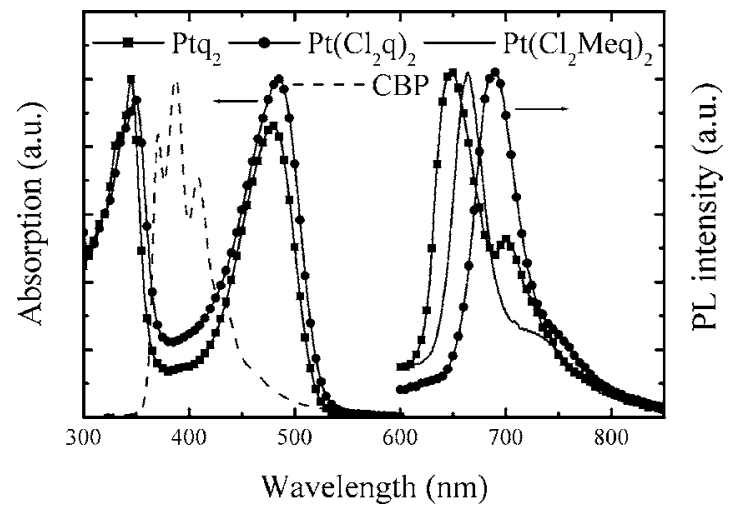

FIG. 3. Absorption spectra of $\mathrm{Ptq}_{2}$ and $\mathrm{Pt}\left(\mathrm{Cl}_{2} \mathrm{q}\right)_{2}$ in DMF solution, and PL emission spectra of thin-film sample of $\mathrm{CBP}, \mathrm{Ptq}_{2}, \mathrm{Pt}\left(\mathrm{Cl}_{2} \mathrm{Meq}\right)_{2}$, and $\mathrm{Pt}\left(\mathrm{Cl}_{2} \mathrm{q}\right)_{2}$ at $298 \mathrm{~K}$.

revealing that the PL emissions come from triplet excitons $\left({ }^{3} \mathrm{ILCT}\right) .{ }^{20}$ The PL quantum efficiency $(\varphi)$ of $\mathrm{Ptq}_{2}$ calculated using an acetonitrile solution of $\left[\mathrm{Ru}(\mathrm{bpy})_{3}\right] \mathrm{Cl}_{2}$ (bpy $=2,2^{\prime}$-bipyridine), as the standard is $1.2 \%$ and $1.0 \%$ in $\mathrm{CH}_{2} \mathrm{Cl}_{2}$ and DMF solution, respectively. The $\varphi$ of $\mathrm{Pt}\left(\mathrm{Cl}_{2} \mathrm{q}\right)_{2}$ is $0.44 \%$ in DMF solution.

The energy levels of $\mathrm{Ptq}_{2}$, calculated using cyclic voltammetric data, are shown in Fig. 2. The energy level of the highest-occupied molecular orbital $(-5.8 \mathrm{eV})$ and lowestunoccupied molecular orbital $(-3.2 \mathrm{eV})$ of $\mathrm{Ptq}_{2}$ match well with that of CBP, therefore, it is suitable to use CBP as the host for $\mathrm{Ptq}_{2}$. All devices started to glow at 3-4 V and gave a deep-red to NIR EL emission similar to the PL emission, indicating that both PL and EL emissions come from triplet excitons. For a dopant concentration of $1.5 \%$, both $\mathrm{Ptq}_{2}$ and $\mathrm{Pt}\left(\mathrm{Cl}_{2} \mathrm{q}\right)_{2}$ gave a little blue emission with a $\lambda_{\max }$ of $420 \mathrm{~nm}$ and a shoulder at $436 \mathrm{~nm}$ from the hole-transport material NPB (Fig. 4). Upon increasing the dopant concentration from $1.5 \%$ to $10 \%$, the EL emission of $\mathrm{Ptq}_{2}, \mathrm{Pt}\left(\mathrm{Cl}_{2} \mathrm{Meq}\right)_{2}$, and $\mathrm{Pt}\left(\mathrm{Cl}_{2} \mathrm{q}\right)_{2}$ show a redshift, attributed to the formation of excimer or oligomer at high dopant concentration. Pt(II) complexes containing chelating anionic ligands are square planar molecules, known to form excimers or oligomer at high complex concentration. ${ }^{13,21}$ The optimal dopant concentrations of $\mathrm{Ptq}_{2}, \mathrm{Pt}\left(\mathrm{Cl}_{2} \mathrm{Meq}\right)_{2}$, and $\mathrm{Pt}\left(\mathrm{Cl}_{2} \mathrm{q}\right)_{2}$ were found to be $3.0,4.5$, and $5.0 \mathrm{wt} \%$, respectively. The maximum $\eta_{\mathrm{ext}}$, luminous efficiency $\eta_{L}$, and turn-on voltage of $3.0 \% \mathrm{Ptq}_{2}$ OLED are $1.7 \%, 0.32 \mathrm{~cd} / \mathrm{A}$, and $3.2 \mathrm{~V} ; 1.3 \%, 0.12 \mathrm{~cd} / \mathrm{A}$, and $3.5 \mathrm{~V}$ for $4.5 \% \mathrm{Pt}\left(\mathrm{Cl}_{2} \mathrm{Meq}\right)_{2}$ OLED, and $0.95 \%$, $0.058 \mathrm{~cd} / \mathrm{A}$, and $3.7 \mathrm{~V}$ for $5.0 \% \mathrm{Pt}\left(\mathrm{Cl}_{2} \mathrm{q}\right)_{2}$ OLED (Fig. 5). For an input voltage from 3 to $16 \mathrm{~V}$, the EL spectra of $3.0 \%$ $\mathrm{Ptq}_{2}, 4.5 \% \mathrm{Pt}\left(\mathrm{Cl}_{2} \mathrm{Meq}\right)_{2}$, and $5.0 \% \mathrm{Pt}\left(\mathrm{Cl}_{2} \mathrm{q}\right)_{2}$ OLEDs exhibit little change, corresponding to pure deep-red light with 1931 Commission Internationale de l'Eclairage (CIE_1931) coordinates of $(0.70,0.29),(0.70,0.28)$, and $(0.71,0.28)$, respectively.

We also note that the maximum $\eta_{\text {ext }}$ of $\mathrm{Ptq}_{2}$ is $1.7 \%$. Thus, the calculated maximum internal quantum efficiency $\left(\eta_{\text {int }}\right)$ of $\mathrm{Ptq}_{2}$ is about $8.5 \%\left(\eta_{\text {int }}=\eta_{\text {ext }} \times 5\right)$. The maximum $\eta_{\text {int }}$ of $\mathrm{Ptq}_{2}$ is much higher than its $\varphi\left(1.2 \%\right.$ in $\mathrm{CH}_{2} \mathrm{Cl}_{2}$ solution). Keeping the excitation wavelength at $350 \mathrm{~nm}$, the $\mathrm{PL}$ intensity of $\mathrm{Ptq}_{2}$ film is very low, which is about $1.0 \%$ of that of CBP film, attributed to the formation of $\mathrm{Pt}(\mathrm{II})$ excimer or oligomer in solid state. In this work, there was no regular decrease in the drive voltage when the concentration of guest AlP license or copyright; see http://apl.aip.org/apl/copyright.jsp 


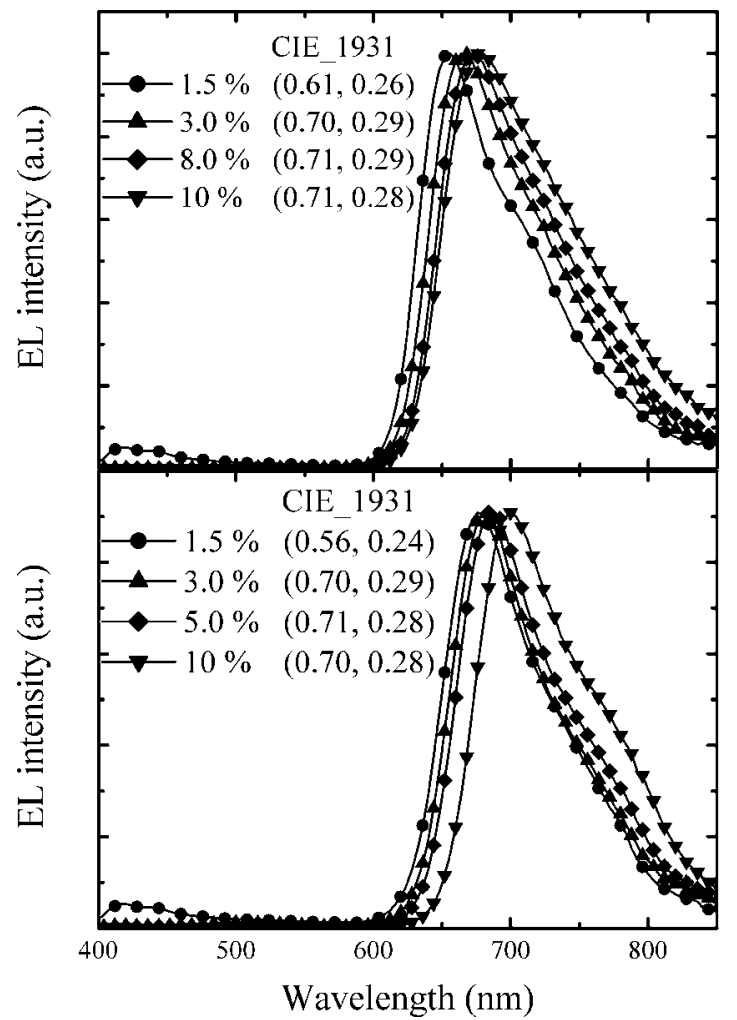

FIG. 4. EL spectra of $\mathrm{Ptq}_{2}$ and $\mathrm{Pt}\left(\mathrm{Cl}_{2} \mathrm{q}\right)_{2}$ at different dopant concentrations with operating voltage at $8 \mathrm{~V}$.

was increased, indicating that the host-guest energy transfer play a more primary role than the charge trapping by dopant. ${ }^{22-24}$ Further evidence can be revealed by the overlap of the absorption spectrum of guest and emission spectrum of the host (Fig. 3). Therefore, the PL intensity of $\mathrm{Ptq}_{2}$ in $3.0 \% \mathrm{Ptq}_{2}$-doped CBP film was increased by a factor of 4.4 compared to that of neat $\mathrm{Ptq}_{2}$ film (excited at $350 \mathrm{~nm}$ ). Although $\eta_{\text {ext }}$ of $\mathrm{Ptq}_{2}$ can reach up to $1.7 \%$, its $\eta_{L}$ is low $(<0.4 \mathrm{~cd} / \mathrm{A})$ because the emission $\lambda_{\max }$ of $\mathrm{Ptq}_{2}$ is over

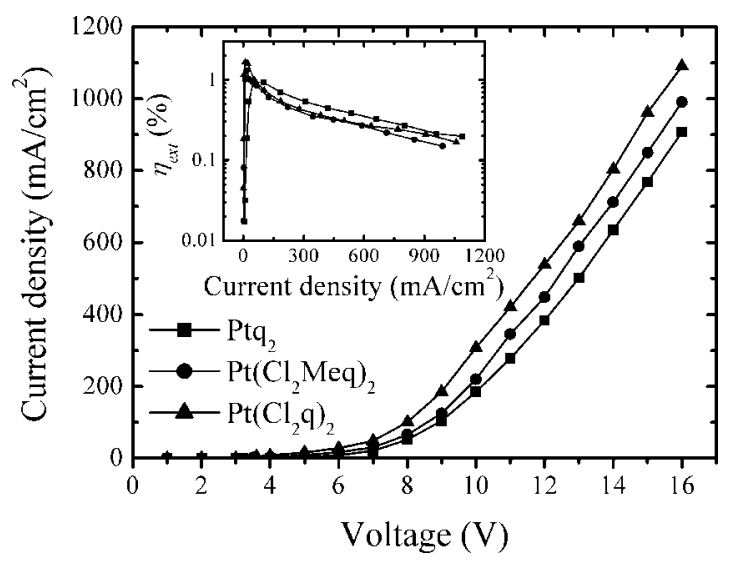

FIG. 5. Current density and external quantum efficiency of $3.0 \% \mathrm{Ptq}_{2}, 4.5 \%$ $\mathrm{Pt}\left(\mathrm{Cl}_{2} \mathrm{Meq}\right)_{2}$, and $5.0 \% \mathrm{Pt}\left(\mathrm{Cl}_{2} \mathrm{q}\right)_{2}$ OLEDs.
$660 \mathrm{~nm}$ and the sensitivity of human eyes is low in this spectral region.

In summary, the photophysical characteristics of phosphorescent bis(8-hydroxquinolato) platinum(II) complexes have been investigated. These Pt(II) complexes give deepred to NIR EL emission ( $\lambda_{\text {max,peak }}, 650-702 \mathrm{~nm}$ and $\lambda_{\text {max,shoulder }}, 720-755 \mathrm{~nm}$ ) with maximum external quantum efficiency, luminous efficiency, and turn-on voltage of $1.7 \%$, $0.32 \mathrm{~cd} / \mathrm{A}$, and $3.2 \mathrm{~V}$, respectively.

This work was supported by the Joint Research Scheme NSFC/RGC (N_HKU 742/04); the University Development Fund (Nanotechnology Research Institute, 00600009) of The University of Hong Kong, the Innovation Technology Fund (ITF), Strategic Theme on Nano-Biotechnology, the Strategic Theme on Organic Electronics, and RGC of HKSAR (Project Nos. HKU 7158/04E and HKU 200607176144).

${ }^{1}$ C. W. Tang and S. A. VanSlyke, Appl. Phys. Lett. 51, 913 (1987).

${ }^{2}$ M. A. Baldo, D. F. O'Brien, Y. You, A. Shoustikov, S. Sibley, M. E. Thompson, and S. R. Forrest, Nature (London) 395, 151 (1998).

${ }^{3}$ L. S. Hung and C. H. Chen, Mater. Sci. Eng., R. 39, 143 (2002).

${ }^{4}$ S. R. Forrest, Nature (London) 428, 911 (2004).

${ }^{5}$ C. Adachi, M. A. Baldo, M. E. Thompson, and S. R. Forrest, J. Appl. Phys. 90, 5048 (2001).

${ }^{6}$ L. H. Slooff, A. Polman, F. Cacialli, R. H. Friend, G. A. Hebbink, F. C. J. M. van Veggel, and D. N. Reinhoudt, Appl. Phys. Lett. 78, 2122 (2001). ${ }^{7}$ F. X. Zang, Z. R. Hong, W. L. Li, M. T. Li, and X. Y. Sun, Appl. Phys. Lett. 84, 2679 (2004).

${ }^{8}$ C. H. Cheng, Z. Q. Fan, S. K. Yu, W. H. Jiang, X. Wang, G. T. Du, Y. C. Chang, and C. Y. Ma, Appl. Phys. Lett. 88, 213505 (2006).

${ }^{9}$ E. L. Williams, J. Li, and G. E. Jabbour, Appl. Phys. Lett. 89, 083506 (2006).

${ }^{10}$ C. J. Yang, C. Yi, M. Xu, J. H. Wang, Y. Z. Liu, X. C. Gao, and J. W. Fu, Appl. Phys. Lett. 89, 233506 (2006).

${ }^{11}$ C. Borek, K. Hanson, P. I. Djurovich, M. E. Thompson, K. Aznavour, R. Bau, Y. Sun, S. R. Forrest, J. Brooks, L. Michalski, and J. J. Brown, Angew. Chem., Int. Ed. 46, 1109 (2007).

${ }^{12}$ Y. Sun, C. Borek, K. Hanson, P. I. Djurovich, M. E. Thompson, J. Brooks, J. J. Brown, and S. R. Forrest, Appl. Phys. Lett. 90, 213503 (2007).

${ }^{13}$ M. Cocchi, D. Virgili, V. Fattori, J. A. G. Williams, and J. Kalinowski, Appl. Phys. Lett. 90, 023506 (2007).

${ }^{14}$ M. Colle and W. Brutting, Phys. Status Solidi B 201, 1095 (2004).

${ }^{15}$ H. F. Xiang, Z. X. Xu, V. A. L. Roy, C. M. Che, and P. T. Lai, Rev. Sci. Instrum. 78, 034104 (2007).

${ }^{16}$ Y. Y. Lin, S. C. Chan, M. C. W. Chan, Y. J. Hou, N. Y. Zhu, C. M. Che, Y. Liu, and Y. Wang, Chem.-Eur. J. 9, 1263 (2003).

${ }^{17}$ C. M. Che, S. C. Chan, H. F. Xiang, M. C. W. Chan, L. Yu, and Y. Wang, Chem. Commun. (Cambridge) 2004, 1484.

${ }^{18}$ C. C. Kwok, H. M. Y. Ngai, S. C. Chan, I. H. T. Sham, C. M. Che, and N. Y. Zhu, Inorg. Chem. 44, 4442 (2005).

${ }^{19}$ R. Ballardini, G. Varani, M. T. Indelli, and F. Scandola, Inorg. Chem. 25, 3858 (1986).

${ }^{20}$ D. Donges, J. K. Nagle, and H. Yersin, Inorg. Chem. 36, 3040 (1997).

${ }^{21}$ H. F. Xiang, S. C. Chan, K. K. Y. Wu, C. M. Che, and P. T. Lai, Chem. Commun. (Cambridge) 2005, 1408.

${ }^{22}$ S. Lamansky, R. C. Kwong, M. Nugent, P. I. Djurovich, and M. E. Thompson, Org. Electron. 2, 53 (2001).

${ }^{23}$ S. C. Chang, G. F. He, F. C. Chen, T. F. Guo, and Y. Yang, Appl. Phys. Lett. 79, 2088 (2001).

${ }^{24}$ B. P. Yan, C. C. C. Cheung, S. C. F. Kui, H. F. Xiang, V. A. L. Roy, S. J. $\mathrm{Xu}$, and C. M. Che, Adv. Mater. (Weinheim, Ger.) 19, 3599 (2007). 